\title{
Comparative Study of Propofol Versus Thiopental Sodium with Succinylcholine for Laryngeal Mask Airway (LMA) Insertion
}

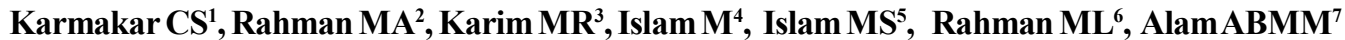

Conflict of Interest: None

Received: $19-02-2018$

Accepted: $22-05-2018$

www.banglajol.info/index.php/JSSMC

\section{Key Words:}

Thiopental Sodium, Propofol, Suxamethonium, Laryngeal Mask Airway (LMA).

\begin{abstract}
:
Background: The increasing emphasis on day case anaesthesia has lead to the greater use of the laryngeal mask airway (LMA) as an alternative to intubation. Laryngoscopy and tracheal intubation are noxious stimuli, which cause a reflex increase in both sympathetic and sympathoadrenal activity that may result in tachycardia, hypertension and dysarrhythmias. Insertion of Laryngeal mask airway (LMA) is associated with less haemodynamic changes, minimal increase in intraocular and intracranial pressure and lower incidence of sore throat. Still its insertion requires sufficient depth of anesthesia to prevent airway reflex (gagging, coughing nd spasms). To insert LMA successfully propofol is the most frequently administered medication. But most of all recommend not using propofol singly for LMA insertion. Thiopental can't suppress the upper airway reflexes as propofol but with low dose succinylcholine upper airway reflexes are attenuated so combination of thiopental sodium with succinylcholine may be another choice of drug.
\end{abstract}

Objectives: This Prospective study was conducted to evaluate the effectiveness of Thiopental sodium and Succinylcholine for insertion of the LMA in comparison with Propofol.

Methods: This interventional study was carried out in Sixty patients, aged 3-45 years who were scheduled for elective surgical procedure under general anaesthesia in ShSMCH. Patients were randomly assigned to two groups by odd and even number basis. In Group-1 $\left(N_{1}=30\right)$, LMA was inserted after induction with Thiopental sodium (5 mg/kg body weight i.v.) and Succinylcholine (0.5mg/kg i.v); in Group-2 $\left(\mathrm{N}_{2}=30\right)$, the LMA was inserted with Propofol (2.5mg/kg i.v). Jaw relaxation, incidence of coughing-gagging, overall insertion condition and haemodynamic changes were observed.

Results: Grade of jaw relaxation in Group-1 was Good in $93.3 \%$, incomplete in $6.7 \%$ and $0 \%$ poor but in Group-2, 86.7\% was good 10\% incomplete and 3.3\% was poor. Coughing occurred in $33.3 \%$ of patients in the Group-2 and there was only $10 \%$ in succinyl group $(\mathrm{P}=0.028)$ which is significantly higher in Group-2. Overall insertion condition in Group -1 was excellent in $86.7 \%$, Good in $10 \%$ cases and poor in only 3.3\% cases on the other hand in Group-2 excellent in $53.3 \%$, Good in $33.3 \%$ cases and poor in only $13.3 \%$ cases $(P=0.019)$.

Conclusion: There was statistically significant difference in jaw relaxation in two groups and incidence of Gagging or Coughing is higher in Group-2. Overall insertion condition was significantly better in Group-1. We concluded that Thiopental sodium with low dose Suxamethonium is an effective alternative of Propofol.

[J Shaheed Suhrawardy Med Coll 2018; 10(1): 11-15] DOI: http://dx.doi.org/10.3329/jssmc.v10i1.38897

1. Dr. Chandra Shekhar Karmakar, Anaesthesiologist, Department of Anaesthesia, Intensive Care and Pain Medicine, Shaheed Suhrawardy Medical College Hospital, Dhaka.

2. Dr. Md. Afzalur Rahman, Junior consultant, Department of Anaesthesia, National Institute of Ear, Nose and Throat, Dhaka

3. Dr. Mohammad Rezaul Karim, Anaesthesiologist, Department of Anaesthesia, Intensive Care and Pain Medicine, Shaheed Suhrawardy Medical College Hospital, Dhaka.

4. Dr. Monirul Islam, Junior Consultant, Department of Anaesthesia, Intensive Care and Pain Medicine, Shaheed Suhrawardy Medical College Hospital, Dhaka.

5. Dr. Md. Shahidul Islam, Assistant Professor, Department of Anaesthesia, Intensive Care and Pain Medicine, Shaheed Suhrawardy Medical College Hospital, Dhaka.

6. Dr. Md. Lutfur Rahman, Associate Professor, Department of Anaesthesia, Intensive Care and Pain Medicine, Shaheed Suhrawardy Medical College Hospital, Dhaka.

7. Prof. ABM Muksudul Alam, Professor \& Head, Department of Anaesthesia, Intensive Care and Pain Medicine, Shaheed Suhrawardy Medical College Hospital, Dhaka.

Correspondence to: Dr. Chandra Shekhar Karmakar, Anaesthesiologist, Dept. of Anaesthesia, Intensive Care and Pain Medicine, Shaheed Suhrawardy Medical College Hospital, Dhaka, Email:cndra42@gmail.com

\section{Introduction}

Laryngeal mask airway (LMA) is the first effective alternative to facemask or tracheal intubation for airway maintenance during anaesthesia ${ }^{1}$. It was conceived, designed, and developed between 1981 and 1988 by Dr. Archie Brain ${ }^{2}$. The LMA rapidly became the standard alternative to tracheal intubation and is the first of the modern supraglottic airway devices (SADs) [also referred to by some as extraglottic airway devices: EADs]. Airway management is one of the most important skills in the field of anaesthesiology, and inability to secure the airway can lead to catastrophic results. The laryngeal mask airway (LMA) is a relatively new device that was brought into clinical practice after 1990, only the face 
mask and the endotracheal tube (ETT) were the available airway devices. Since then several supraglottic airway devices have been developed, of which the laryngeal mask airway (LMA) is the most popular one. However its insertion is not always achieved easily, a gentle technique is of great importance throughout this procedure. Appropriate depth of anaesthesia along with sufficient muscle relaxation is required to prevent complication as well as smooth insertion of LMA. To insert LMA successfully propofol is the most frequently administered medication. Various study favoured Propofol as better induction agent than Thiopental in LMA insertion. Sometimes it is difficult to insert LMA properly only with Propofol, moreover propofol is not always available in our rural seetings, so an alternative way should be searched to tackle all situations wherever it arises. For that reason Thiopental sodium along with low dose Suxamethonium could be a better alternative.

Since LMA had been introduced there were many studies carried out for its insertion but in our country very few studies conducted earlier. So it was planned to do this study to find out the success rate of LMA insertion using Thiopental sodium with Suxamethonium in comparison with Propofol.

\section{Methods}

This prospective randomized study was carried out after approval of hospital ethics committee of Shaheed Suhrawardy Hospital from 01/01/2014 to 30/06/2014 (6 months period). 60 patients were randomly selected according to the inclusion criteria. Inclusion criteria for the study subjects were a) age 3-45 years, b) ASA grades I \& II, c) Body weight less than $70 \mathrm{~kg}$, d) Patients who will be undergone for elective body surface area surgery, e) Tentative duration of operation not more than 90 minutes. The procedure was explained to the patients or parents gurdian during pre anaesthetic check up at least twentyfour hours prior to surgery. Written informed consent was obtained and a careful physical examination was done to exclude patients with other problems.

Patients were randomly assigned to two groups by odd and even number basis. In Group-1 $\left(\mathrm{N}_{1}=30\right)$, LMA was inserted after induction with Thiopental sodium $(5 \mathrm{mg} / \mathrm{kg}$ body weight i.v.) and Succinylcholine $(0.5 \mathrm{mg} / \mathrm{kg}$ i.v); in Group-2 $\left(\mathrm{N}_{2}=30\right)$, the LMA was inserted with Propofol $(2.5 \mathrm{mg} / \mathrm{kg}$ i.v). All patient received $100 \%$ oxygen for $5 \mathrm{~min}$ via facemask and pethidine $0.5 \mathrm{mg} / \mathrm{kg}$ i.v. before administering induction agent. After giving induction agent and confirming that the patient had lost consciousness and jaws were relaxed adequately LMA was attempted to insert. If more than one attempt was required patient was kept anaesthetized by inhalation of Halothene.

Jaw relaxation was graded according to criteria of Young, Clarke, and Dundee ${ }^{3}$. Overall insertion condition was assessed by modified scheme of grading of intubation conditions by Lund and Stovner ${ }^{4}$. Incidence of gagging or coughing on insertion was scored on a four point scale according to Nimmo and collegues ${ }^{5}$. Incidence of laryngospasm and other complication was also noted.

All patient were fasted 4-10 hours. A pulse oxymeter and an automated non-invasive arterial blood pressure monitor was applied. Heart rate, Systolic, diastolic and mean arterial pressures were noted just before and after induction and also 5 minutes after LMA insertion.

All the data was checked and edited after collection. Then the data was entered into computer and analyzed with the help of SPSS-16.0 (Statistical package for social sciences) windows version 16.0 software programme. Statistical analysis was performed using Chi-square test, MannWhitney $U$ and Independent sample t test to compare patient groups. $\mathrm{p}<0.05$ was considered statistical significant. All probability values quoted were 2 -tailed.

\section{Results}

There was no significant differences $(\mathrm{p}=0.683)$ in Demographic characteristics between the 2 groups. Age and sex distribution shows (in table1, table-2) detail

\section{Table-I}

\begin{tabular}{lccc}
\multicolumn{4}{c}{ Distribution of age by group } \\
Age (in year) & Group 1 & Group 2 & p value* \\
\hline $3-10$ & $12(40.0)$ & $13(43.3)$ & \\
$10-20$ & $12(40.0)$ & $10(33.3)$ & \\
$20-30$ & $3(10.0)$ & $4(13.3)$ & \\
$30-45$ & $3(10.0)$ & $3(10.0)$ & \\
Total & $30(100.0)$ & $30(100.0)$ & \\
Mean \pm SD & $14.80 \pm 9.59$ & $15.30 \pm 9.67$ & \\
Median & 11.0 & 12.0 & 0.683 \\
\hline
\end{tabular}

*Mann-Whitney U test was done to measure the level of significance.

Figure within parenthesis indicates in percentage.

Participents took part in this project were in age group of 3-45 years. Mean age of Group-1 was $14.80 \pm 9.59$ and in Group-2 was $15.30 \pm 9.67$ years and p value $0.683(\mathrm{p}>0.05)$. 
Table-II

\begin{tabular}{lccc} 
& \multicolumn{3}{c}{ Distribution of sex by group } \\
Sex & Group 1 & Group 2 & p value* \\
Male & $18(60.0 \%)$ & $17(56.7 \%)$ & 0.793 \\
Female & $12(40.0 \%)$ & $13(43.3 \%)$ & \\
\hline Total & $30(100.0 \%)$ & $30(100.0 \%)$ & \\
\hline
\end{tabular}

*Chi-square test was done to measure the level of significance.

We have also weight restriction in our protocol (weight $<70 \mathrm{~kg}$ ). We found mean weight of our study population was 35.07 \pm 18.63 in Group-1 and 36.27 \pm 17.75 in Group-2,

$\mathrm{p}$ value was $0.912(>.05)$.the value between those two groups is insignificant.

\section{Table-III}

Distribution of weight by group

\begin{tabular}{lccc} 
Weight (in kg) & Group 1 & Group 2 & p value* \\
\hline $10-25$ & $16(53.3)$ & $13(43.3)$ & \\
$25-40$ & $4(13.3)$ & $5(16.7)$ & \\
$40-55$ & $4(13.3)$ & $6(20.0)$ & \\
$55-70$ & $6(20.0)$ & $6(20.0)$ & \\
Total & $30(100.0)$ & $30(100.0)$ & \\
Mean \pm SD & $35.07 \pm 18.63$ & $36.27 \pm 17.75$ & \\
Median & 24.5 & 31.5 & 0.912 \\
\hline
\end{tabular}

*Mann-Whitney U test was done to measure the level of significance.

Figure within parenthesis indicates in percentage.

All vital signs were recorded from 5 minutes before induction up to end of operation.

\section{Table-IV}

\begin{tabular}{lccc}
\multicolumn{4}{c}{ Distribution heart rate by group } \\
Heart rate & Group 1 & Group 2 & p value* \\
Before LMA & $91.13 \pm 13.22$ & $89.67 \pm 13.60$ & 0.673 \\
insertion & & & \\
$5 \mathrm{~min}$ & $97.93 \pm 14.15$ & $96.13 \pm 15.28$ & 0.638 \\
$20 \mathrm{~min}$ & $90.57 \pm 12.18$ & $88.27 \pm 12.36$ & 0.471 \\
$40 \mathrm{~min}$ & $90.17 \pm 12.62$ & $87.47 \pm 12.10$ & 0.401 \\
$60 \mathrm{~min}$ & $92.42 \pm 10.33$ & $88.21 \pm 8.50$ & 0.266 \\
\hline
\end{tabular}

*t test was done to measure the level of significance.

Data was present as Mean $\pm \mathrm{SD}$.
There was no significant difference in heart rate after induction and post-insertion between the two groups.SpO2 and mean blood pressure were also recorded throughout operation but there was no significant difference found between two groups. None of the patients suffered any serious adverse events during this study.

\section{Jaw relaxation}

Jaw relaxation was graded as $1=$ good, $2=$ incomplete or $3=$ poor according to the classification by Young, Clark and Dundee. Grade of jaw relaxation found satisfactory in both group.Jaw relaxation in Group-1 was good in 28 patient $(93.3 \%)$ in comparison with Group-2 where jaw relaxation was Good in 26 patient $(86.7 \%)$ difference was not statistically significant $p$ value $0.529 .(>0.05)$

Table-V

Distribution Grade of jaw relaxation by group

\begin{tabular}{lccc}
$\begin{array}{l}\text { Grade of jaw } \\
\text { relaxation }\end{array}$ & Group 1 & Group 2 & p value* \\
Good & $28(93.3)$ & $26(86.7)$ & \\
Incomplete & $2(6.7)$ & $3(10.0)$ & 0.529 \\
Poor & $0(.0)$ & $1(3.3)$ & \\
Total & $30(100.0)$ & $30(100.0)$ & \\
\hline
\end{tabular}

*Chi-square test was done to measure the level of significance.

Figure within parenthesis indicates in percentage.

\section{Incidence of gagging or coughing}

Incidence of gagging or coughing on insertion were score on a scale according to Nimmo and collegeagues. Incidence of gagging or coughing was significantly lower in Group- $1(\mathrm{p}=0.028)$ only 3 patient of succinyl Group having mild coughing.

\section{Table VI}

Distribution Incidence of gagging or coughing during LMA insertion by group

Incidence of Group $1 \quad$ Group 2 p value* gagging or coughing during

LMA insertion

\begin{tabular}{lccc}
\hline Yes & $3(10.0)$ & $10(33.3)$ & 0.028 \\
No & $27(90.0)$ & $20(66.7)$ & \\
Total & $30(100.0)$ & $30(100.0)$ &
\end{tabular}

*Chi-square test was done to measure the level of significance.

Figure within parenthesis indicates in percentage. 


\section{Overall insertion condition:}

Overall insertion condition was significantly better in Group-1( $\mathrm{P}=0.019)$. Excellent insertion condition obtained in $86.7 \%$ patient in Group -1 , whereas only $53.3 \%$ cases in Group-2, insertion condition was poor in only $1(3.3 \%)$ patient in Group -1, and 4 (13.3\%) in Group -2.

\section{Table-VI}

\begin{tabular}{lccc}
\multicolumn{4}{c}{ Distribution } \\
Overall insertion conditions & by group \\
conditions & & Group 2 & p value* \\
\hline Excellent & $26(86.7)$ & $16(53.3)$ & \\
Good & $3(10.0)$ & $10(33.3)$ & 0.019 \\
Poor & $1(3.3)$ & $4(13.3)$ & \\
\hline Total & $30(100.0)$ & $30(100.0)$ & \\
\hline
\end{tabular}

*Chi-square test was done to measure the level of significance.

Figure within parenthesis indicates in percentage.

8 patients in Group - 2 required $2^{\text {nd }}$ attempt in LMA insertion but all 28 (93.33\%) patient of Group -1 were inserted in first attempt.

\section{Table-VIII}

Number of attempts required for LMA insertion.

\begin{tabular}{lccc} 
& Group 1 & Group 2 & P value \\
\hline 1 & $28(93.33 \%)$ & $22(73.33 \%)$ & 0.3752 \\
$>1$ & $2(6.66 \%)$ & $8(26.66 \%)$ & \\
\hline
\end{tabular}

\section{Discussion}

Since the introduction of the laryngeal mask airway, various methods have been evaluated in order to make its insertion smooth, with least side effects and cost effectiveness. The insertion of an LMA requires suppression of upper airway reflexes to prevent coughing, gagging or laryngospasm. ${ }^{6}$ Since propofol is the induction agent of choice for LMA insertion but propofol alone, in standard dose does not provide the best insertion conditions. ${ }^{6-9}$

The use of muscle relaxant provides a better insertion condition for propofol and thiopentone as induction agent. Depolarizing muscle relaxants have a far better effect than non-depolarizing drugs ${ }^{9}$. Succinylcholine is the only available depolarizing neuromuscular blocker. It is characterized by rapid onset of effect and ultrashort duration of action. Administration of $1 \mathrm{mg} / \mathrm{kg}$ of succinylcholine results in complete relaxation in 60 seconds . Probable side effects are prolonged apnea, anaphylaxis,and myalgia. Intubating dose of succinylcholine is $1-2 \mathrm{mg} / \mathrm{kg}$ and a very small dose of succinylcholine $(0.1 \mathrm{mg} / \mathrm{kg})$ is effective in relieving laryngospasm without prolonged apnea. ${ }^{10}$ In our study ease of insertion of LMA and the excellent insertion conditions were obtained in $86.7 \%$ of patients in group- 1 compared to $53.3 \%$ of group- $2 .(P=0.019)$ There was significant less incidence of head and limbs movement, coughing or laryngospasm in group -1. These findings are consistent with those by Korula et al. ${ }^{6}$ Compared succinyl choline $0.35 \mathrm{mg} / \mathrm{kg}$ with $0.08 \mathrm{mg} / \mathrm{kg}$ of atracurium for LMA insertion during thiopentone induction and they found that succinyl choline provided better insertion conditions as there was no coughing or gagging, and minimal patient movement. Monem and Chohan, ${ }^{11}$ comparing succinylcholine $0.35 \mathrm{mg} / \mathrm{kg}$ with atracurium $0.06 \mathrm{mg} / \mathrm{kg}$ under thiopentone induction, found excellent insertion conditions with succinylcholine group in $83 \%$ as against $46 \%$ for that of atracurium. There was no failure in the succinylcholine group compared with $17 \%$ failure rate with atracurium. ${ }^{11}$ If there were airway reflexes coughing, gagging, head or limb movement preventing LMA.

The success rate of LMA insertion in the first attempt was $93.33 \%$ in succinylcholine group and $73.33 \%$ in control group and the difference was statistically significant.( $P=0.0375)$. W.T Salem and S. Jamil reported successful LMA insertion in $90 \%$ of patients in the first attempt in succinylcholine group. 8,12

\section{Conclusion}

Overall, we concluded that LMA insertion by Thiopental sodium with Suxamethonium produces better condition than Propofol, moreover it's also cost effective in comparing our socioeconomic condition. Though study population was selected from one selected hospital in Dhaka city with a very short period of time and sample size was quite small so the findings derived from study cannot be generalized to reference population.

\section{References}

1. Uerpairojkit K, Charuluxananan S, Werawatganon T, et al. Profile Soft-Seal Cuff for General Anesthesia under Ambulatory Gynecologic. J Med Assoc Thai 2009;92(9): 1184-90.

2. Pollard BJ, Norton ML. Principle of airway management. Wylie and Churchill Davidson's A practice of anesthesia. $7^{\text {th }}$ edition, 2003; 443-464. 
3. Young HAS, Clarke RSJ, Dundee JW. Intubating conditions with AH 8165 and suxamethonium, Anaesthesia 1975; 30: 30-3

4. Lund I, Stonver J. Dose-response curves for tubocurarine, alcuronium and pancuronium.Acta Anaesthesiol Scand 1970; 37S: $238-42$

5. Nimmo SM, McCann N, Broome IJ, Robb HM.Effectiveness and sequelae of very low-dose suxamethonium for nasal intubation. Br J Anaesth 1995; 74:31-4

6. Korula S, Abraham V, Afzal L. Evaluation of Low Dose Succinylcholine for Insertion of Laryngeal Mask Airway During Thiopentone Induction: A Comparison with Atracurium. J Anaesth Clin Pharmacol 2010;26:355-359.

7. Jamil SN, Singhal V, Habib SK. The Effect of mini dose Suxamethonium to facilitate Laryngeal Mask Airway Insertion Under Propofol Anesthesia. Rawal Medical Journal $2010 ; 35: 2-5$.
8. Parhizgar Kh, Afridi Y. Comparison Between Propofol and Thiopentone Sodium for Laryngeal Mask Insertion in Day Case Surgery .JPMI 2008: 22: 238-242.

9. Monem A, Khan FA. Laryngeal Mask Airway Insertion Anesthesia and Insertion Techniques. J Pak Med Assoc 2007;57:607-611.

10. Naguib M ,Lien CA. Pharmacology of Muscle Relaxants and their Antagonists.In:Miller RD.(2010).Miller,s Anesthesia,1,7th ed.Churchill Livingstone,Elsevier,859-903.

11. Monem A,Chohan U. Comparison of Low Dose Succinylcholine with Low Dose Atracurium to Evaluate Laryngeal Mask Airway Insertion During Thiopental Induction.J Anesth Clin Pharmacol 2004;20;39-44.

12. Salem WT. A Comparison of Midazolam and Mini-Dose Succinylcholine to aid Laryngeal Mask Airway Insertion During Propofol Anesthesia.Journal of Egyptian Nat. Cancer Inst 2000;12:65-69. 